\title{
Multiple Regeneration from Axolotl Limb Stumps Bearing Cross-Transplanted Minced Muscle Regenerates
}

\author{
Bruce M. Carlson ${ }^{1}$ \\ Hubrecht Laboratory, Utrecht, The Netherlands and Department of Anatomy, University of Michigan, Ann \\ Arbor, Michigan $48104^{2}$
}

Accepted March 7, 1975

\begin{abstract}
Flexor and extensor muscles in the upper arms of axolotls were minced and cross-transplanted. The limbs were amputated 5 and 30 days after mincing. In each experiment a high percentage of the regenerates consisted of multiple limbs. This demonstrates that the morphogenetic information which produces multiple regenerates after the cross-transplantation of limb stump muscle is stable enough to be expressed after both mincing and the subsequent tissue regeneration of the muscle.
\end{abstract}

\section{INTRODUCTION}

Several investigators have shown that rotation of the skin $180^{\circ}$ around the proximodistal (Pr-Ds) axis in the urodele forelimb causes the formation of multiple regenerates after amputation of the limb through the rotated skin (Droin, 1959; Settles, 1967; Lheureux, 1972; Carlson, 1974a). Similarly, the rotation of muscles about the Pr-Ds axis to heterotopic sites within the limb is also known to cause supernumerary regeneration after amputation (Lheureux, 1972; Carlson, 1974b). In addition, Carlson (1974b) has dissociated gross rotation into two components: 1) rotation of a muscle about the Pr-Ds axis in situ (with minimal positional displacement) and 2) positional change without axial rotation (accomplished by cross-transplantation of muscles). Positional change alone of flexor and extensor muscles in the stump results in $90 \%$ regeneration of complex multiple limbs whereas $180^{\circ}$ axial rotation of the flexor and extensor muscles in situ is followed by $20-30 \%$ multiple regenerates of a simple type, primarily duplications at the tips of digits.

\footnotetext{
${ }^{1}$ This investigation was supported by a grant from the Muscular Dystrophy Association of America.

${ }^{2}$ Present address: Department of Anatomy, University of Michigan, Medical Science II, Ann Arbor, MI 48104.
}

Neither the nature nor the mode of transmission of the morphogenetic influence demonstrated by the aforementioned experiments is known. This report presents experiments designed to determine whether or not the morphogenetic information can survive severe mechanical disruption of the tissues bearing it. To investigate this, minced muscle regeneration was combined with positional displacement of muscle groups. Entire limb muscles in the axolotl are known to regenerate after mincing (Carlson, 1970a). In the following experiments upper arm muscles were removed, minced and transplanted into heterotopic positions within the limb, after which the limbs were amputated. The specific question asked in this experiment was, Can limb muscles that have undergone mincing and subsequent tissue regeneration retain and subsequently express their morphogenetic (positional) information during limb regeneration?

\section{MATERIALS AND METHODS}

These experiments were performed on 2-3-year-old axolotls $(200-280 \mathrm{~mm})$ raised in the Hubrecht Laboratory. All animals were anesthetized in 1:1000 MS-222 (Sandoz) during the operation. The upper arm flexor and extensor muscles were removed and minced into $1-\mathrm{mm}^{3}$ fragments, as pre- 
viously reported for a hindlimb muscle (Carlson, 1970a). After transplantation, the skin incision was sutured with Ethicon 7-0 silk. All amputations were carried out through the distal third of the humerus. Three experimental series were conducted. The design of each will be described along with the results.

\section{RESULTS}

\section{Series I; Control (Fig. I)}

In eight upper arms the flexor and extensor muscle groups were removed, minced and replaced into their original beds. The minced muscles were allowed to regenerate for 11 days before the arms were amputated proximal to the elbow. Seven $(87.5 \%)$ of the arms produced normal four-digit regenerates. The remaining regenerate terminated as a broad, blunt knob with no digits. In no case did the trauma of mincing alone stimulate the formation of multiple regenerates.

Series II, Cross-Transplantation of Minced Muscles Followed by Limb Amputation 30 Days Later (Fig. 2)

In 11 axolotls the flexor and extensor muscles of the upper right arm were minced. The minced flexor muscle tissue was cross-transplanted into the bed of the extensor muscles and vice versa. As controls, the flexor and extensor muscles of the left arms were cross-transplanted intact. In addition they were axially rotated $180^{\circ}$ (anteroposterior and dorsoventral axial reversal). After 30 days all limbs were amputated through the level of the transplanted muscles. Thirty days is sufficient time for a minced muscle in the axolotl to be replaced by newly regenerating crossstriated muscle fibers (Carlson, 1970a). Nine $(81.8 \%)$ of the limbs bearing crosstransplanted minced muscle regenerates produced multiple regenerates (Fig. 3). One $(9.1 \%)$ regenerate was normal and one $(9.1 \%)$ was a three-digit hypomorphic limb. This percentage of multiple regeneration exceeded that of the control limbs bearing intact transplants $(63.6 \%$ multiple regenerates). The latter percentage of multiple regenerates was lower than that normally seen in experiments involving the displacement of intact stump muscles, but it may merely represent the lower end of the normal range of variability. The range of complexity of the multiple regenerates is presented in Table 1.

This experiment demonstrates not only that the morphogenetic information in question survives the mincing procedure but that it is also retained during the subsequent tissue regenerative process.

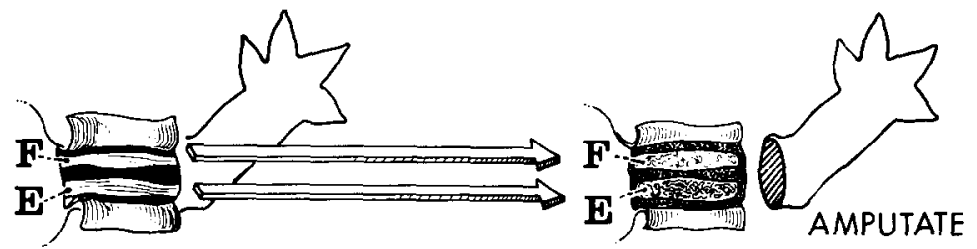

MINCE FLEXOR \& EXTENSOR

MUSCLES AND REPLACE IN SITU

REGENERATES

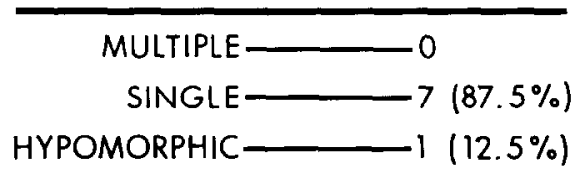

Fig. 1. Experimental design and summary of the results of Series I. 


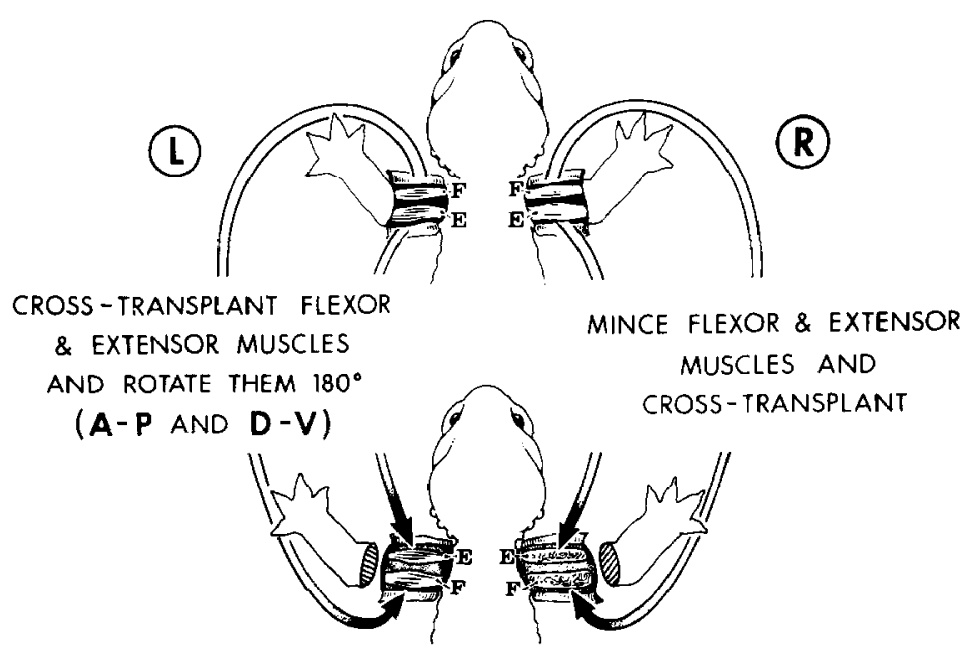

AMPUTATE AFTER 30 DAYS

REGENERATES

\begin{tabular}{cccc}
\hline & MULTIPLE & SINGLE & HYPOMORPHIC \\
\hline INTACT (D) & $7(63.6 \%)$ & $4(36.4 \%)$ & 0 \\
MINCED (R) & $9(81.8 \%)$ & $1(9.1 \%)$ & $1(9.1 \%)$
\end{tabular}

FIG. 2. Experimental design and summary of the results of Series II.

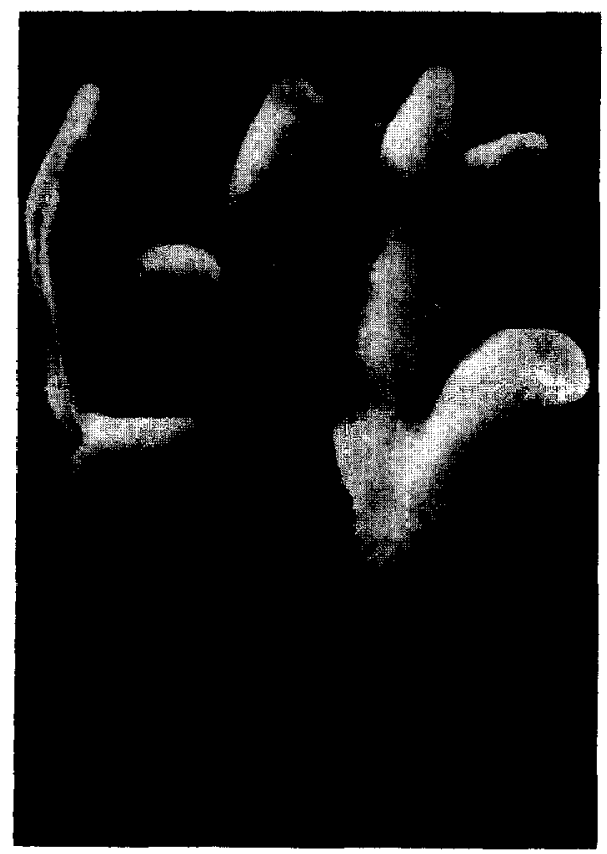

Series III, Cross-Transplantation of Minced Muscles Followed by Limb Am. putation 5 Days Later (Fig. 4)

Five days after mincing, an axolotl muscle is still in a state of morphological disruption. Almost all original fragments of the implanted muscle are still recognizable. The broken muscle fibers are ischemic, and some sarcoplasmic removal by macrophages has occurred. Even at the periphery, the newly regenerating muscle is represented almost entirely by spindle-shaped myoblasts. This experiment was designed to determine whether cross-transplanted

FIG. 3. Ventral view of a nine-digit right regenerate. The flexor and extensor muscles were minced, cross-transplanted and allowed to regenerate for 30 days before the limb was amputated. The regenerate was photographed 105 days after amputation. 
minced muscles in an early stage of tissue regeneration are also capable of influencing the morphology of an epimorphically regenerating limb.

In 14 axolotls the right flexor and extensor muscles were minced and cross-transplanted as described in Series II. The left flexor and extensor muscles were trans-

TABLE 1

Numbers of Digits Found in Multiple Regenerates from Series II (Limb Amputation 30 Days After

Cross-Transplantation of the Muscle)

\begin{tabular}{ccc}
\hline $\begin{array}{c}\text { No. of } \\
\text { digits }\end{array}$ & $\begin{array}{c}\text { Left } \\
\text { (intact muscle) }\end{array}$ & $\begin{array}{c}\text { Right } \\
\text { (minced muscle) }\end{array}$ \\
\hline 5 & 3 & 5 \\
6 & 1 & \\
7 & 3 & 1 \\
8 & & 1 \\
8 & & 1 \\
9 & & 1 \\
10 & $\overline{\mathrm{x}}=6.0$ digits & $\overline{\mathrm{x}}=6.6$ digits \\
\hline
\end{tabular}

planted intact. In contrast to the preceding series, the cross-transplanted intact muscles were not axially rotated. Rotation of the cross-transplanted muscles was not performed because other concurrent experiments had by this time shown that rotation of cross-transplanted muscles is not necessary to produce high percentages of multiple regenerates (Carlson, 1974b). All upper arms were amputated 5 days later.

Thirteen $(92.9 \%)$ of the right arms bearing minced muscles produced multiple regenerates averaging 6.2 digits (Table 2), a somewhat higher percentage than that occurring from stumps bearing 30-day minced muscle regenerates (Series II). As in Series II, the percentage of multiple regeneration on the experimental side was higher than that $(78.6 \%)$ in limbs bearing intact transplants.

This experiment demonstrates that cross-transplanted minced muscles do not

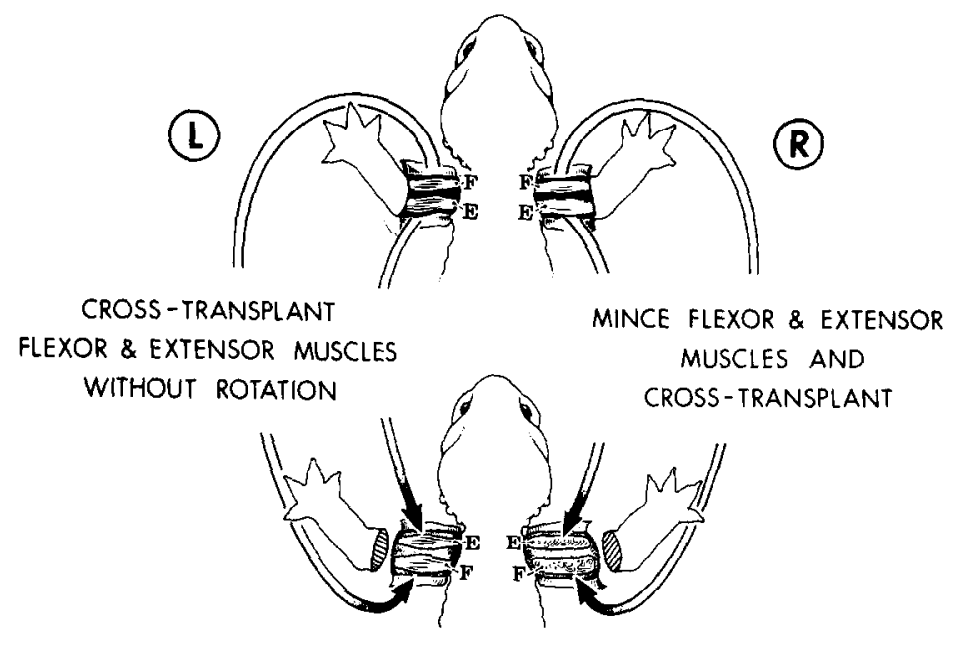

AMPUTATE AFTER 5 DAYS

REGENERATES

\begin{tabular}{lll}
\hline & MULTIPLE & SINGLE \\
\hline INTACT (D) & $11(78.6 \%)$ & $3(21.4 \%)$ \\
MINCED (R) & $13(92.9 \%)$ & $1(7.1 \%)$
\end{tabular}

Fig. 4. Experimental design and summary of the results of Series III. 
TABLE 2

Numbers of Digits Found in Multiple Regenerateis from Series III (Limb Amputatión 5 Days After Cross-Transplantation of the Muscle)

\begin{tabular}{ccc}
$\begin{array}{c}\text { No. of } \\
\text { digits }\end{array}$ & $\begin{array}{c}\text { Left } \\
\text { (intact muscle) }\end{array}$ & $\begin{array}{c}\text { Right } \\
\text { (minced muscle) }{ }^{a}\end{array}$ \\
\hline 5 & 1 & 5 \\
6 & 5 & 2 \\
7 & 2 & 4 \\
8 & 1 & 1 \\
9 & 1 & \\
10 & & \\
11 & 1 & $\overrightarrow{\mathrm{x}}=6.2$ digits \\
12 & $\overline{\mathrm{x}}=7.1$ digits
\end{tabular}

${ }^{a}$ One regenerate from this series was fixed for histology before digit formation was completed and was not included in this tabulation. It would have produced at least 6-7 digits.

have to regenerate new multinucleated muscle fibers in order to exert their morphogenetic influence.

\section{DISCUSSION}

These experiments demonstrate that positionally dislocated tissues in a $\operatorname{limb}$ stump need not retain their structural integrity in order to exert a morphogenetic influence upon a regenerating limb. Mincing breaks axolotl muscle into packets of 25-50 segments of muscle fibers. Within each minced fragment, the relationship of one muscle fiber to the other remains unchanged. Soon after mincing, however, the old muscle fibers begin to degenerate. The muscle fragments then contain interstitial connective tissue, degenerating muscle fibers invaded by macrophages, and a population of myogenic cells of unknown origin located beneath the degenerating basement membranes of the origi nal muscle fibers.

From this experiment one can almost certainly eliminate the normal intact architecture of a tissue as a primary factor in the transmission of its morphogenetic information after it has been positionally displaced. Instead, it is most likely that the information in question resides in or on the cells of that tissue. This conclusion is strengthened by the results of previous work involving $\mathrm{X}$-radiation of rotated tissues (Rahmani and Kiortsis, 1961; Carlson, 1974a). In these experiments if either the skin or underlying stump tissues were irradiated and the skin was subsequently rotated $180^{\circ}$, multiple regeneration did not occur. How $\mathrm{X}$-radiation influences and inhibits regeneration remains obscure, but the overall tissue architecture of the limb stump is not visibly changed.

The experiment in Series II brings to light another major difference between the tissue and the epimorphic regeneration of muscles (Carlson, 1970b). Both gross and internal morphogenesis in a tissue regenerative process appear to be controlled entirely by mechanical factors mediated by the functional environment surrounding the regenerating muscle (Carlson, 1972). There is no evidence for the operation of morphogenetic factors similar to those that occur during the embryogenesis or epimorphic regeneration of muscles. In Series II, the morphogenetic information that leads to multiple regenerates after limb amputation was not expressed during the tissue regeneration of the cross-transplanted minced muscles. Similarly, in experiments conducted on mammals (Gutmann and Carlson, 1975) cross-transplanted limb muscles in the rat give no evidence of a morphogenetic disturbance during the tissue regeneration that accounts for the success of the free muscle grafts.

In addition to answering the question posed in the introduction, this research also demonstrates that the yet undefined morphogenetic influence leading to multiple regeneration can be used as a very stable tissue (and perhaps cellular) marker. In that respect it has helped to answer an oft-recurring criticism of the minced muscle technique; namely, that the minced muscle degenerates and disappears and that the new muscle tissue is formed by ingrowth from the surround- 
ing tissues. If that were the case in these experiments, one would not expect the limbs regenerating after amputation to be multiple. The lack of discrimination between influences of different cell types, however, does not allow one to say that the morphogenetic effect is due solely to the muscle cells themselves, for it could also be due entirely to the connective tissue component of the muscle or both components together.

I thank the Hubrecht Laboratory for providing the animals and facilities for this research. The illustrations were prepared by Mr. William L. Brudon.

\section{REFERENCES}

Carlson, B. M. (1970a). The regeneration of a limb muscle in the axolotl from minced fragments. Anat. Rec. 166, 423-436.

Carlson, B. M. (1970b). Relationship between the tissue and epimorphic regeneration of muscle. Amer. Zool. 10, 175-186.

Carlson, B. M. (1972), "The Regeneration of Minced Muscles," Monographs in Developmental Biology,
Vol. 4. S. Karger, Basel.

Carlson, B. M. (1974a). Morphogenetic interactions between rotated skin cuffs and underlying stump tissues in regenerating axolotl forelimbs. Develop. Biol. 39, 263.285.

Carlson, B. M. (1974b). Morphogenetic effects of cross-transplanted muscles upon an epimorphic regenerative process (Abstract). III Int. Congr. Muscle Diseases (ICS No. 334), 117.

Droin, A. (1959). Potentialités morphogènes dans la peau du triton en régénération. Rev. Suisse Zool. 66, 641-709.

Gutmann, E., and Carlson, B. M. (1975). Contractile and histochemical properties of regenerating crosstransplanted fast and slow muscles in the rat. Pflügers Arch. 353, 227-239.

Lheukeux, E. (1972). Contribution à l'etude du rôle de la peau et des tissus axiaux du membre dans le déclenchement de morphogenèses régénératrices anormales chez le triton Pleurodeles waltlii Michah. Ann. Embryol. Morphog. 5, 165-172.

Rahmani, T., and Kiortsis, V. (1961). Le rôle de la peau et des tissus profonds dans la régénération de la patte. Rev. Suisse Zool. 68, 91-102.

Settles, H. E. (1967). "Supernumerary Regeneration Caused by Ninety Degree Skin Rotation in the Adult Newt, Triturus viridescens." Ph.D. thesis, Tulane University, New Orleans. 